\title{
An unusual manifestation: Papillary thyroid carcinoma in a patient with ataxia-telengiectasia
}

\author{
Ezgi Ulusoy ${ }^{1}$, Neslihan Edeer-Karaca ${ }^{1}$, Samim Özen ${ }^{1}$, Yeşim Ertan², Damla Gökşen ${ }^{1}$, \\ Güzide Aksu'1, Şükran Darcan ${ }^{1}$, Necil Kütükçüler ${ }^{1}$ \\ Departments of ${ }^{1}$ Pediatrics and ${ }^{2}$ Pathology, Ege University Faculty of Medicine, Izmir, Turkey. \\ E-mail: ezgiulusoy13@hotmail.com \\ Received: 6th November 2015, Revised: 25th February 2016, Accepted: 12th April 2016
}

\begin{abstract}
SUMMARY: Ulusoy E, Edeer-Karaca N, Özen S, Ertan Y, Gökşen D, Aksu G, Darcan Ş, Kütükçüler N. An unusual manifestation: Papillary thyroid carcinoma in a patient with ataxia-telengiectasia. Turk J Pediatr 2016; 58: 442-445.

Ataxia-telangiectasia (A-T) is a rare autosomal recessive, multisystem, neurodegenerative disorder, characterized by oculocutaneous telangiectasias, variable immunodeficiency and progressive neurological impairment. Definitive diagnosis is made by revealing a disease causing mutation on ATM gene. Missense mutations and polymorphisms of ATM gene can play a role in the development of thyroid papillary carcinoma.

A 13-year-old Turkish girl was diagnosed with ataxia telengiectasia at the age of 8 years. When she was 12 years old, multi-nodular goiter was detected by physical examination and ultrasonography. She underwent thyroidectomy and histopathologic investigation revealed a papillary carcinoma with follicular variant. The patient received post-operative radioiodine therapy as well as L-thyroxine treatment because she had residual lesions. Up until now, she is the first Turkish child wit A-T and thyroid carcinoma described in the literature.
\end{abstract}

Key words: ataxia telengiectasia, papillary thyroid carcinoma.

Ataxia-telangiectasia (A-T) is a rare autosomal recessive, multisystem, neurodegenerative genetic disorder. It is characterized by oculocutaneous telangiectasias, variable immunodeficiency and progressive neurological abnormalities such as uncoordinated, ataxic movements as a result of cerebellar cortical degeneration ${ }^{1-2}$. Other features include retardation of somatic growth, premature aging, radiosensitivity and predisposition to cancer ${ }^{2}$. Definitive diagnosis is made by revealing a disease causing mutation on ATM gene which was identified in 1995 in 11q22-23, coding for a protein implicated in genomic homeostasis in case of radio-induced DNA double-strand breaks $^{1-3}$.

Mutations in ATM gene predispose patients to cancer. The cancer incidence for homozygotes is 100 -fold greater than that of the general population ${ }^{4}$. Although the exact mechanisms of malignant transformation in A-T patients is not known, loss of cell cycle control, a defect in DNA repair, or sensitivity to radiation may be responsible 4 . Lymphoid malignancies of both $\mathrm{B}$ cell and $\mathrm{T}$ cell origin, including non-Hodgkin and Hodgkin lymphoma and several forms of leukemia are reported in A-T patients.

Thyroid papillary carcinoma is the most common carsinoma of thyroid gland, but thyroid carcinomas are rare in childhood. Missense mutations and polymorphisms of ATM gene can play a role in the development thyroid papillary carcinoma ${ }^{5-9}$. Both DNA double-strand break repair pathway and thyroid morphogenesis pathway or dysregulation of thyroid differentiated state maintenance are involved in the etiology of papillary thyroid carcinoma ${ }^{10}$.

We report a 13-year-old girl with ataxia telengiectasia, who developed thyroid papillary carcinoma during follow-up. To our knowledge, she is the first Turkish A-T child with thyroid carcinoma described in the literature. 


\section{Case Report}

A 13-year-old Turkish girl, was first referred to our department because of ataxic movements, ocular telengiectasia and recurrent sinopulmonary infections when she was 8 years old. She was born to unrelated healthy parents at 40th gestational week. Her physical examination showed ocular telengiectasia, strabismus, ataxia, disartria, dismetria, nystagmus and positive Romberg test. She had hypogammaglobulinemia; IgG:512 mg/ dl (840-1240 mg/dl), IgA: $<5 \mathrm{mg} / \mathrm{dl}$ (68-150 $\mathrm{mg} / \mathrm{dl})$, IgM: $155 \mathrm{mg} / \mathrm{dl}(55-140 \mathrm{mg} / \mathrm{dl})$ high alpha-feto protein; $169,3 \mathrm{ng} / \mathrm{dl}(0-14 \mathrm{ng} / \mathrm{ml})$ levels and inverted CD4/CD8 ratio. Cranial MRI showed cerebellar hemisphere and vermis hypoplasia. She was diagnosed with ataxia telengiectasia and genetic analysis revealed an ATM gene mutation (3' UTR. + 548 G>T heterozygous, $+551 \mathrm{~T}>\mathrm{C}$ heterozygous). She was treated with regular intravenous immunoglobuline (IVIG) replacement therapy and antibiotics prophylaxis. During followup, she had experienced lower respiratory tract infections requiring parenteral antibiotic therapy once or twice a year. When she was 10 years, she developed ulcerated plaques on her right hand second metacarpophalangeal joint. Skin biopsy showed granulomatous lesion with caseification necrosis with negative acidfast stain. She had antituberculosis treatment and local corticosteroids, with unremarkable response.

At the age of 12 years, multiple thyroid nodules were observed by routine physical examination. The biggest one was painless with $2 \mathrm{~cm}$ in diameter on the right lobe of thyroid gland. Thyroid ultrasonography revealed a $26 \times 18 \mathrm{~mm}$ solid nodule on the right thyroid lobe, and multiple nodules on both lobes. There was no cervical lymphadenopathy. Thyroid scintigraphy showed multi-nodular goiter with multiple hypoactive nodules on both lobes. The family history for thyroid abnormalities or cancer was negative, and there was no history of previous neither cervical nor chest irradiation. Laboratory investigations showed normal thyroid function tests (TSH: $1.66 \mathrm{mU} / \mathrm{ml}$, free T4: 0,97 $\mathrm{ng} / \mathrm{dl}$ ) and negative autoimmune markers (Anti-TPO: $35 \mathrm{IU} / \mathrm{ml}$, Anti-TG:<20 IU/ $\mathrm{ml}$ ). Thorax magnetic resonance imaging (MRI) and abdominal MRI were negative for metastatic lesions. Computerized tomography was not preferred for metastatic imaging because of radiosensitivity. The patient underwent total thyroidectomy. Histopathological examination revealed a papillary carcinoma with follicular variant, with no vascular invasion but minimal capsular invasion (Fig.1). Immunohistochemical staining showed positive immunoreactivity for cyclin D1 and cytokeratin 19, and was negative for galectin-3. Thyroid Tc-99m pertechnetate scintigraphy showed residual thyroid tissue after the surgery. Postoperative Anti-Tg levels were also $<20 \mathrm{IU} / \mathrm{ml}$. L-thyroxine treatment was started and the patient received post-operative radioiodine therapy.

\section{Discussion}

Ataxia-telangiectasia is an autosomal recessive rare multisystem neurodegenerative disorder characterized by oculocutaneous telangiectasias, immunodeficiency and progressive neurological abnormalities. Radiation-induced chromosomal breakage is a hallmark of A-T 11,12. The incidence of A-T is approximately 1 in 100,000 live births. A-T is caused by biallelic mutations in the ATM gene, located on chromosome 11q22.3-23.1. Since the localization of the ATM gene to chromosome 11, over 500 different ATM mutations have been identified. The ATM gene encodes for the protein kinase ATM, a key player in the cellular response to double-stranded DNA damage and multiple cell cycle checkpoint pathways. Malignancy risk is approximately 100 times greater than in the general population ${ }^{4}$. Studies pointed to a high incidence of lymphoid malignancies In patients with A-T, most notably T-cell acute lymphoblastic leukemias. B-cell non-Hodgkin lymphoma and Hodgkin lymphoma were also reported to be frequent ${ }^{13,14}$. In A-T patients, death is usually because of pulmonary infections or malignancies.

Thyroid carcinomas are very rare in childhood, consisting of approximately $0.5 \%$ to $3 \%$ of all pediatric malignancies and the incidence increases after 10 year of age with a predominance in females ${ }^{15,16}$. Thyroid nodules in pediatric patients are four times more likely to be malignant than in adult patients. Papillary thyroid carcinoma is the predominant type of thyroid cancer. Although pathophysiology of differentiated thyroid carcinoma is not well 

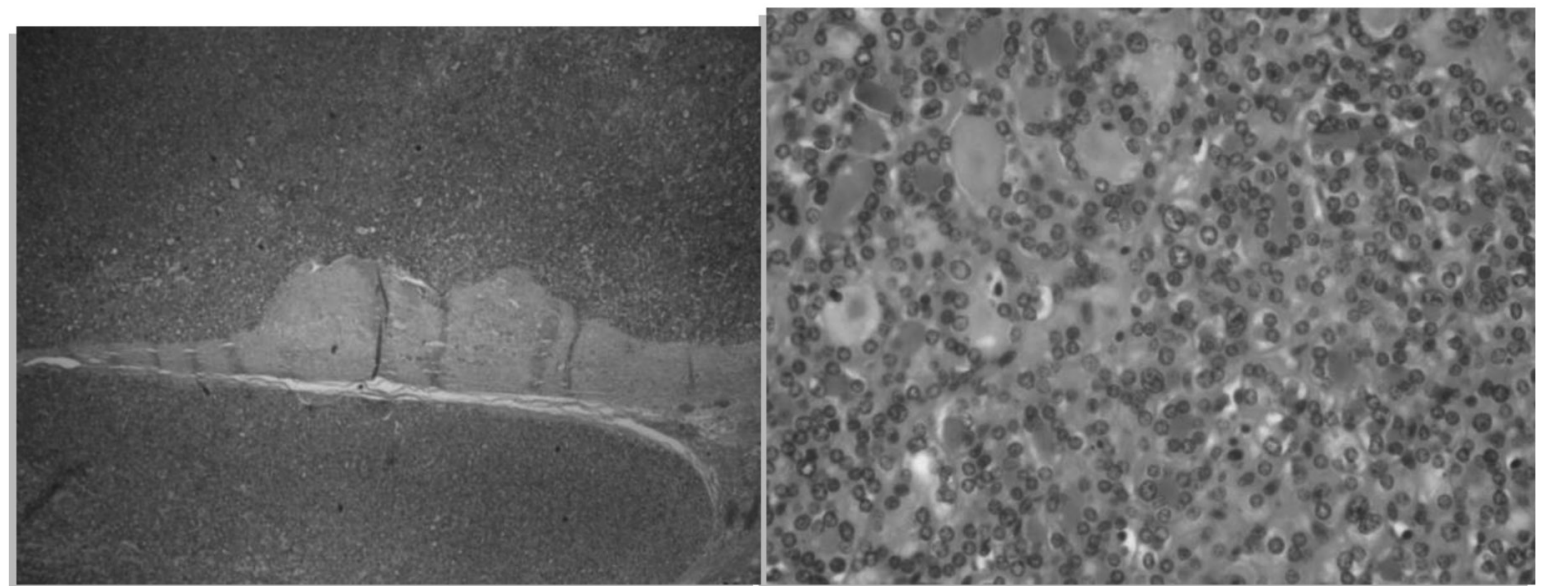

Fig. 1. A) Capsule invasion in minimal invasive carcinoma B) Classical nucleolar charasteristics in papillary thyroid carcinoma

defined, exposure to ionizing radiation is known to be a risk factor. Ionizing radiation causes a variation of DNA damages. A-T cells are characterized by an extreme sensitivity of DNA to radiomimetic agents because of alteration of cell-cycle inhibition in response to radiation exposure. ATM gene polymorphisms can be a risk factor for thyroid carcinomas (8). First relatives of A-T patients can also develop solid tumors such as breast carcinomas.

Patient reported here is the first Turkish child who developed papillary thyroid carcinoma with A-T. There is only one other A-T child reported by Brasseur et $a^{3}$; that was a 9-yearold girl with papillary carcinoma. Suarez et al. ${ }^{13}$ identified 279 patients with A-T and revealed 69 patients with cancer. Sixty-one of whom were hematologic malignancies. Only one of their patients had thyroid carcinoma. Sandoval et al. ${ }^{14}$ reported two A-T patients one with follicular thyroid carcinoma, the other with papillary thyroid carcinoma. Even if malignancy risk is greater than normal population in A-T patients, solid tumors are rare than hematologic malignancies. Unfortunately, subsequent risk of developing another malignancy, especially with hematologic origin, is higher in patients with solid tumors. Hecht et al. ${ }^{17}$ reported that approximately $25 \%$ of A-T patients with solid tumors subsequently developed non-Hodgkin lymphoma or leukemia, whereas a very low risk of subsequent neoplasms existed when the first tumor was lymphoid in origin. As the patient had solid tumor at first, she is being periodically screened for neoplasias closely.
In the treatment of thyroid cancers, the best option is the complete surgical resection of the thyroid gland with central lymph node dissection followed by radioactive iodine treatment. Our patient underwent total thyroidectomy. There was no vascular invasion. Because Thyroid Tc- $99 \mathrm{~m}$ pertechnetate scintigram showed residual throid tissue after the surgery, she received radioactive iodine treatment. After 6 months, she is euthyroid and well.

In conclusion, children with ataxia-telangiectasia can develop solid tumors as well as hematologic malignancies. During follow-up, physicians must be alert for thyroid nodules as well as the other malignancies. Early treatment will affect mortality and morbidity.

\section{REFERENCES}

1. Azarsiz E, Karaca NE, Gunaydin NC, et al. Do elevated serum IgM levels have to be included in probable diagnosis criteria of patients with ataxia-telangiectasia? Int J Immunopathol Pharmacol 2014; 27: 421-427.

2. Chaudhary MW, Al-Baradie RS. Ataxia-telangiectasia: future prospects. Appl Clin Genet 2014; 7: 159-167.

3. Brasseur B, Beauloye V, Chantrain C, et al. Papillary thyroid carcinoma in a 9-year-old girl with ataxiatelangiectasia. Pediatr Blood Cancer 2008; 50: 10581060.

4. Sandoval C, Schantz S, Posey D, Swift M. Parotid and thyroid gland cancers in patients with ataxiatelangiectasia. Pediatr Hematol Oncol 2001; 18: 485490.

5. Song CM, Kwon TK, Park BL, Ji YB, Tae K. Single nucleotide polymorphisms of ataxia telangiectasia mutated and the risk of papillary thyroid carcinoma. Environ Mol Mutagen 2015; 56: 70-76. 
6. Dombernowsky SL, Weischer M, Allin KH, Bojesen SE, Tybjaerg-Hansen A, Nordestgaard BG. Risk of cancer by ATM missense mutations in the general population. J Clin Oncol 2008; 26: 3057-3062.

7. Xu L, Morari EC, Wei Q Sturgis EM, Ward LS. Functional variations in the ATM gene and susceptibility to differentiated thyroid carcinoma. J Clin Endocrinol Metab 2012; 97: 1913-1921.

8. Gu Y, Yu Y, Ai L, Shi J, Liu X, Sun H, Liu Y. Association of the ATM gene polymorphisms with papillary thyroid cancer. Endocrine 2014; 45: 454-461.

9. Wójcicka A, Czetwertyńska M, Świerniak M, et al. Variants in the ATM-CHEK2-BRCA1 axis determine genetic predisposition and clinical presentation of papillary thyroid carcinoma. Genes Chromosomes Cancer 2014; 53: 516-523.

10. Damiola $\mathrm{F}^{1}$, Byrnes $\mathrm{G}$, Moissonnier M, et al. Contribution of ATM and FOXE1 (TTF2) to risk of papillary thyroid carcinoma in Belarusian children exposed to radiation. Int J Cancer 2014; 134: 16591668.

11. Nagasravani J, Chacham S, Narayan Reddy U, Narsing Rao J, Rao SP, Mahmood A. A rare case of ataxia telangiectasia in a 9-year-old female child. Pediatr Neurol 2014; 51: 583-584.
12. Chopra C, Davies G, Taylor M, Anderson M, Bainbridge $S$, Tighe P, McDermott EM. Immune deficiency in Ataxia-Telangiectasia: a longitudinal study of 44 patients. Clin Exp Immunol 2014; 176: 275-282.

13. Suarez F, Mahlaoui N, Canioni D, et al. Incidence, presentation, and prognosis of malignancies in ataxiatelangiectasia: a report from the French national registry of primary immune deficiencies. J Clin Oncol 2015; 33: $202-208$

14. Sandoval C, Swift M. Hodgkin disease in ataxiatelangiectasia patients with poor outcomes. Med Pediatr Oncol 2003; 40: 162-166.

15. Chung BM, Park SH, Kim SJ, Seo JS, Kim YS, Shim HJ, Lee JB. Papillary thyroid carcinoma in children and adolescents. Ultrasound Q 2014; 30: 193-196.

16. Noh BJ , Sung JY, Kim YW, Park YK. Recurrent thyroid papillary carcinoma in children under ten years old: report of two cases and literature review. Korean J Pathol, 2014; 48: 297-301.

17. Hecht F, Hecht BK. Cancer in ataxia-telangiectasia patients. Cancer Genet Cytogenet 1990; 46: 9-19. 